\title{
Identification of semiaquatic avifauna species in shallow waters of the Don River delta using an autonomous remote-controlled midget floating craft
}

\author{
Oleg Khoroshev ${ }^{1,{ }^{*}}$, Ramiz Savitskiy ${ }^{1}$, Pavel Plyaka ${ }^{1,2}$, Georgiy Valov ${ }^{1}$, and Valerian \\ Ivanov $^{1}$ \\ ${ }^{1}$ Federal Research Centre The Southern Scientific Centre of the Russian Academy of Sciences (SSC \\ RAS), 41 Chekhov Street, 344006, Rostov-on-Don, Russian Federation \\ ${ }^{2}$ Don State Technical University, 1 Gagarin square, 344003, Rostov-on-Don, Russian Federation
}

\begin{abstract}
A survey method for identifying avifauna in shallow areas of the Don River delta has been developed and tested using a prototype of an autonomous remote-controlled and self-propelled floating craft equipped with technical means for optical-visual observation and video filming (hereafter referred as the complex). The complex is remote-controlled by an operator. The methodology of the work included designing the complex and testing it in open water bodies, reconnaissance of the shallow water bodies in the Don River delta where the complex might navigate, the approbation of the panoramic video recording of birds, and processing of the recorded video for identification of the species. The complex is able to reliably collect visual information on the move as well as being stationed at points for bird observation. Thanks to the test missions of the complex, the selected shallow areas of the Don River delta were explored for the first time and reviewed by panoramic video recording. The 16 birds were captured in the footage, and 7 out of them were reliably identified. The panoramic video records can be also used for educational purposes. The developed complex has a relatively low manufacturing cost and can be assembled in a university lab too.
\end{abstract}

\section{Introduction}

The deltas of lowland rivers cross vast areas of natural and natural-anthropogenic landscapes. Usually, the deltaic plains are lowlands gently sloping to the seas, separated by shallow branches, channels, and eriks on numerous islands. River deltas are a natural refuge for birds and a place of their mass nesting. There are 161 bird species in the Don River delta, most of which belong to the semiaquatic avifauna [1-5].

Many reservoirs of river deltas are hardly accessible because they are shallow, covered with dense vegetation, etc. Inaccessibility poses difficulties for ornithologists practicing traditional field methods for identifying avifauna species. It is arduous to implement the

\footnotetext{
* Corresponding author: ourregion@mail.ru
} 
point count method and area search in a coastal zone with extensive reed thickets due to the constantly changing width of view and the depth of exploration. Instead, counting birds along lines would be more convenient. There are plenty of works dedicated to the methodology of setting and performing the ornithological monitoring, and in particular, to the transect count method, where the observer travels along lines and counts all birds within a strip [6-11]. In the authors' opinion, the most suitable modern means for ornithological observations along lines in hard-to-reach areas of the river delta are floating crafts and drones (unmanned aerial vehicles). Observation of birds from ships and small vessels is traditional and a fairly effective method [12-14]. Like any method, it is not free of drawbacks, including the accessibility of water reservoir for the vessel due to the shallowness, the narrowness of individual eriks and channels, the presence of abundant aquatic vegetation, the need for ground transportation of the vessel to remote isolated bodies of water. Also, an observed onboard of the ship is exposed to various natural hazards, and a big vessel may frighten and disturb birds.

Autonomous remote-controlled midget floating crafts (ARMFC) equipped with systems for optical-visual observation area surging tool for the effective and low-cost monitoring of avifauna in shallow and hard-to-reach delta areas of large flat rivers. The idea is not new; the first such vessel was invented by Nikola Tesla in 1898. According to the work of Lyakhov et al. [15], early experiments with unmanned vessels took place in the post-war period. The systemic development of Unmanned Surface Vessels (USV) began in the early 1990sand continuing until today, being operated by different state-owned and commercial organizations around the globe [16].

Modern technologies have made it possible to bring all advantages of USV in an ultrasmall autonomous watercraft, which can automatically collect visual information and take the probes in a vast variety of water bodies, saving labor costs and energy resources. ARMFC is controlled remotely by an operator and can carry the equipment for sound recording and optical-visual observation. It navigates to the observation point using a satellite positioning system, then makes the photo, audio, and video recording for a long time, triggered by events or remote commands. The records are memorized in a compressed form and then sent to the operator across wireless networks. For the studies in hydrology and hydrochemistry, the parameters of the aquatic environment, such as temperature, salinity, the content of dissolved oxygen can be determined at the observation points by contact methods.

Analysis of the literature has shown that the use of ARMFC for environmental monitoring has been steadily increasing worldwide. The main producers of commercial ARMFC (Teledyne Oceanscience, Aerrobotix, etc.) choose the catamaran or trimaran hulls. The examples are the compact autonomous surface vehicle "HydroNet ASV" for monitoring of water quality [17] and the autonomous floating mobile craft "ZiviCat" for limnological research [18], both were assembled on a catamaran base.

The objective of the current study was to develop and test a method for identifying semiaquatic avifauna in shallow areas of the Don River delta using the ARMFC prototype developed by the authors. ARMFC was equipped with cameras for shooting 360-degree videos (VR $360^{\circ}$ ). This was the first time when the selected shallow areas of the Don River delta were accessed for monitoring and the advanced video techniques were applied for the birds count. Analysis of video sequences captured at the observation point during the test mission of ARMFC allowed us to locate and identify several flying birds. Based on the field experience the methodology of using ARMFC for semiaquatic avifauna studies was developed to be implemented in the high school courses on ornithology. 


\section{Materials and methods of research}

To achieve the objectives of the research, the team of authors developed the ARMFC prototype, called "Vodomerka" ("water strider" in Russian). It is built on the frame of a commercially available mini-trimaran "Riverboat ST" ("Teledyne Oceanscience"; the model is discontinued) using commercial devices and modules of our manufacture. The mini-trimaran with a built-in profiler was already employed for investigations in the Don River delta and confirmed the reliability of its design. The hull of the mini-trimaran is made of high strength polymer material. The mini-trimaran has a low draft with good stability on the water surface. Despite a small size, it offers sufficient space for the accommodation of various equipment.

The ARMFC "Vodomerka" is composed of the following units (Fig. 1). The three hulls are joined by metal crossbars with the lattice aft over. It bears a waterproof deck, containing two Li-ion batteries $(12 \mathrm{~V} / 30 \mathrm{Ah})$ with a charge-discharge control board, a GNSS RTK satellite positioning system with an OEM ODM antenna, a radio modem, a controller for two propellers, and for a rudder with an accelerometer, compass, and gyroscope, power converter $(12 \mathrm{~V} / 5 \mathrm{~V})$, remote control receiver, and on-screen indicator unit. The course controller with in-house software provides synchronization of thrust, angular movement of the rudder, forward and reverse movement. There are two propellers in the stern with the movable nozzles to improve maneuverability. Waterproof brushless speed controllers with a water cooling system are used to control the power of the propellers. Within the GSM coverage area, data is being sent via radio modem with a transmission rate of up to 14.4 $\mathrm{kb} / \mathrm{s}$. ARMFC is guided by the operator by means of a remote control panel and an FPV video helmet $(800 \times 480 / 5.8 \mathrm{GHz})$, which receives a video signal from an FPV video camera with a transmitter $(200 \mathrm{~mW} / 5.8 \mathrm{GHz})$ on board. The technical characteristics of the ARMFC "Vodomerka" are summarized in Table 1.

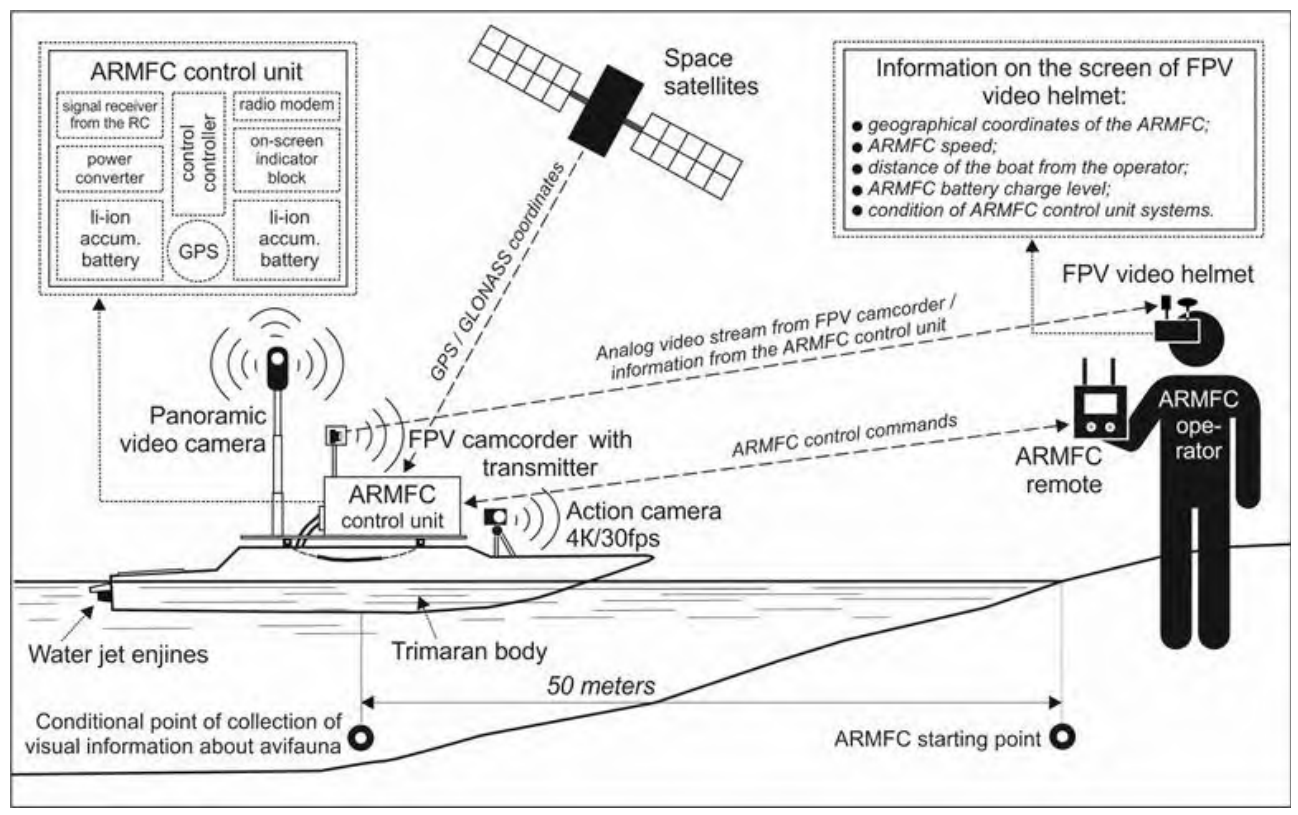

Fig. 1.ARMFC "Vodomerka" schematic. The modified Riverboat ST is configured with a deck for the control unit. ARMFC is equipped with cameras for counting birds. Its mission is controlled by the operator, who wears the FPV helmet and uses the remote control panel for commands. More details are provided in the text. 
Table1. Some technical characteristics of ARMFC "Vodomerka" for the birds counting.

\begin{tabular}{|c|c|c|}
\hline Property & Value & Comment \\
\hline Dimensions $(\mathrm{L} / \mathrm{W} / \mathrm{H}), \mathrm{cm}$ & $120 / 80 / 31$ & Height includes the control unit \\
\hline Wight, kg & 16 & Without cameras \\
\hline Draft, cm & 5 & Without cameras and attachments \\
\hline Lifting capacity, $\mathrm{kg}$ & up to 10 & $\begin{array}{l}\text { Hull with the control unit and } \\
\text { propellers }\end{array}$ \\
\hline Power reserve, $\mathrm{h}$ & 2 & Two batteries and low-speed movement \\
\hline Maximum speed, knots & up to 10 & In open water \\
\hline Turning radius, $\mathrm{m}$ & 1.65 & On still water \\
\hline $\begin{array}{l}\text { Radius of signal transmission from the } \\
\text { control panel, } \mathrm{m}\end{array}$ & up to 1000 & $\begin{array}{l}\text { Depends on obstacles on the way of } \\
\text { transmitted signal }\end{array}$ \\
\hline $\begin{array}{l}\text { Transmission radius of analog image to } \\
\text { FPV helmet, } m\end{array}$ & up to 500 & $\begin{array}{l}\text { Depends on obstacles on the way of } \\
\text { transmitted signal }\end{array}$ \\
\hline $\begin{array}{l}\text { Radius of Wi-Fi signal transmission from } \\
\text { a panoramic video camera, } \mathrm{m}\end{array}$ & up to 20 & $\begin{array}{l}\text { Depends on obstacles on the way of } \\
\text { transmitted signal }\end{array}$ \\
\hline $\begin{array}{l}\text { Maximum battery life of a panoramic } \\
\text { video camera, min }\end{array}$ & up to 60 & $\begin{array}{l}\text { In continuous shooting mode. Depends } \\
\text { on air temperature }\end{array}$ \\
\hline
\end{tabular}

The functioning of ARMFC is controlled on a distance (even out-of-sight) by the operator wearing the FPV helmet. On the helmet's screen, the operator sees a real-time video being transmitted from ARMFC, as well as auxiliary data about the geolocation, the speed of movement, the distance from the operator, the level of battery charge, and the status of the ARMFC control unit (Fig. 2). All transmitted data is saved in the built-in memory card. The maximum distance from the operator to ARMFC is defined by the transmission radius of the FPV equipment and should not exceed $500 \mathrm{~m}$.

For the bird counting three digital cameras were employed:

1) a mini FPV camera (1/3" CMOS matrix)with the maximum video resolution of 600TVLand the ability to transmit a streaming video to the FPV helmet;

2) an action camera (1/2.3" CMOS matrix) with the maximum video resolution of $3840 \times 2160$ (4K / 30fps) in a widescreen mode with the ability to transmit streaming digital images via Wi-Fi module;

3) a panoramic $\left(\mathrm{VR} 360^{\circ}\right)$ camera $\left(1 / 2.3^{\prime \prime} \mathrm{CMOS}\right)$ with the maximum video resolution of $5760 \times 2880(5.7 \mathrm{~K} / 30 \mathrm{fps})$ and the ability to send a streaming video over Wi-Fi module.

Since the panoramic camera has been employed for the first time for the bird counting, a few more technical details will be given. The camera has two 200-degree wide-angle lenses and its software automatically merges the captured images into a single panoramic view. It can work in either "Bullet time" and "Time-Lapse" shooting modes, providing sequences of high-quality images for further analysis. The waterproof box protects the equipment from raindrops and elevated humidity.

ARMFC can capture visual data either on the move or in a standby mode at the observation points. In the former mode, the video shooting is carried out at a speed of 5-6 knots, which is optimal for high-quality panoramic filming of birds alarmed by the noise from the moving ARMFC. It is advisable to have the observation points separated by the distance of $50 \mathrm{~m}$ and move between them at a low speed of 1-2 knots. The duration of work at every point was not exceeding $20 \mathrm{~min}$ for the 3-point line and $30 \mathrm{~min}$ for the 2-point one. The operation time can be extended to the desired duration by connecting the camera to additional batteries onboard with the USB cable. It is better to have the ARMFC body covered with a camouflage except for the lenses.

The test field missions were performed in the shallow areas of the Don River delta in May-June 2020 in several locations, highlighted in Fig. 2. They were visited for making the motion tests of ARMFC, the examination of equipment functioning, and the observation of 
vegetation along the channels. Then a reed-overgrown drainage channel (the starting point was at $47.201325,39.391854$ ) and a small silted lake (the starting point was at 47.213423, 39.387288) in the shallow areas were chosen specifically for the birds counting (Fig. 2). These areas are inaccessible (or hardly accessible) for ornithological observations by traditional means. They were selected from the pre-assessment studies, performed earlier in surrounding territories by traditional methods with the use of vehicles, boats, and drones as well as during the explorative visits on foot.

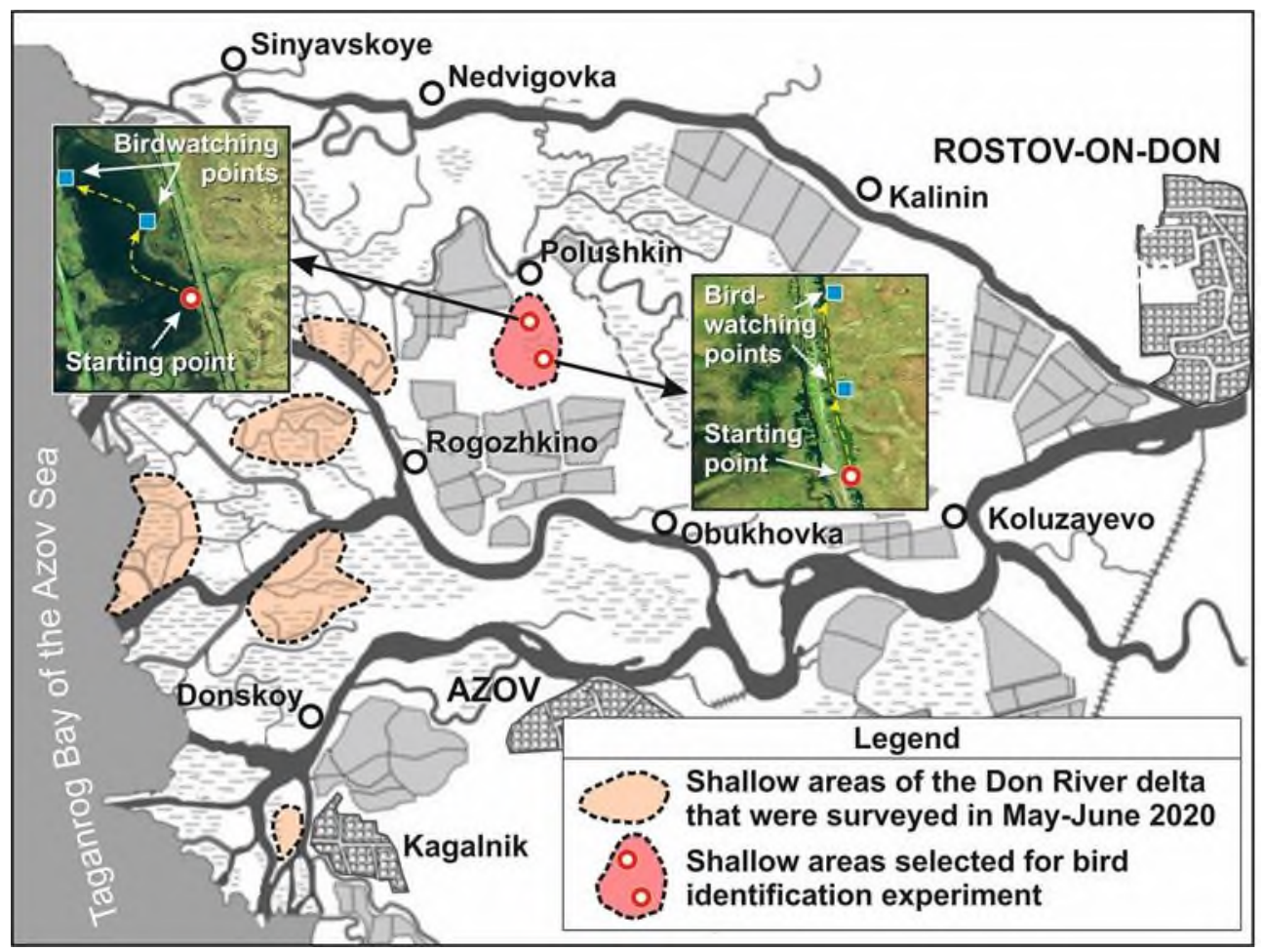

Fig. 2. Layout of the investigated shallow areas in the Don River delta by means of ARMFC, including the areas where the birds counting was performed.

The exploratory methodology, which has been developed for identifying semiaquatic avifauna in shallow areas of the Don River delta by means of ARMFC can be summarized as the following sequence of steps:

1) setting the desired configuration of ARMFC by a modular design. It means selecting the cameras and additional equipment for measurements and supply;

2) performing the in-door and out-door tests of ARMFC in the selected configuration to ensure its stable functioning (the control unit onboard, the remote control system, communication and shooting equipment);

3) carrying out the reconnaissance of water reservoirs in the Don River delta for the explorative missions and performing test navigation in a similar water body as the last check of ARMFC.

4) executing the explorative mission of ARMFC by recording the panoramic video at scheduled observation points along the lines in shallow areas of the Don River delta.

5) processing of the recorded video and identification of captured avifauna species. 


\section{Results and discussion}

Before the explorative missions, the field tests of ARMFC were performed in reservoirs of the Don River delta during the spring-summer period (Fig. 3). ARMFC demonstrated good stability against the waves up to 4 points according to the Beaufort Scale, the ability to carry a payload up to $10 \mathrm{~kg}$, and the high speed and maneuverability in waters with abundant aquatic vegetation. These tests allowed to confirm the advantages and to identify the disadvantages of ARMFC.
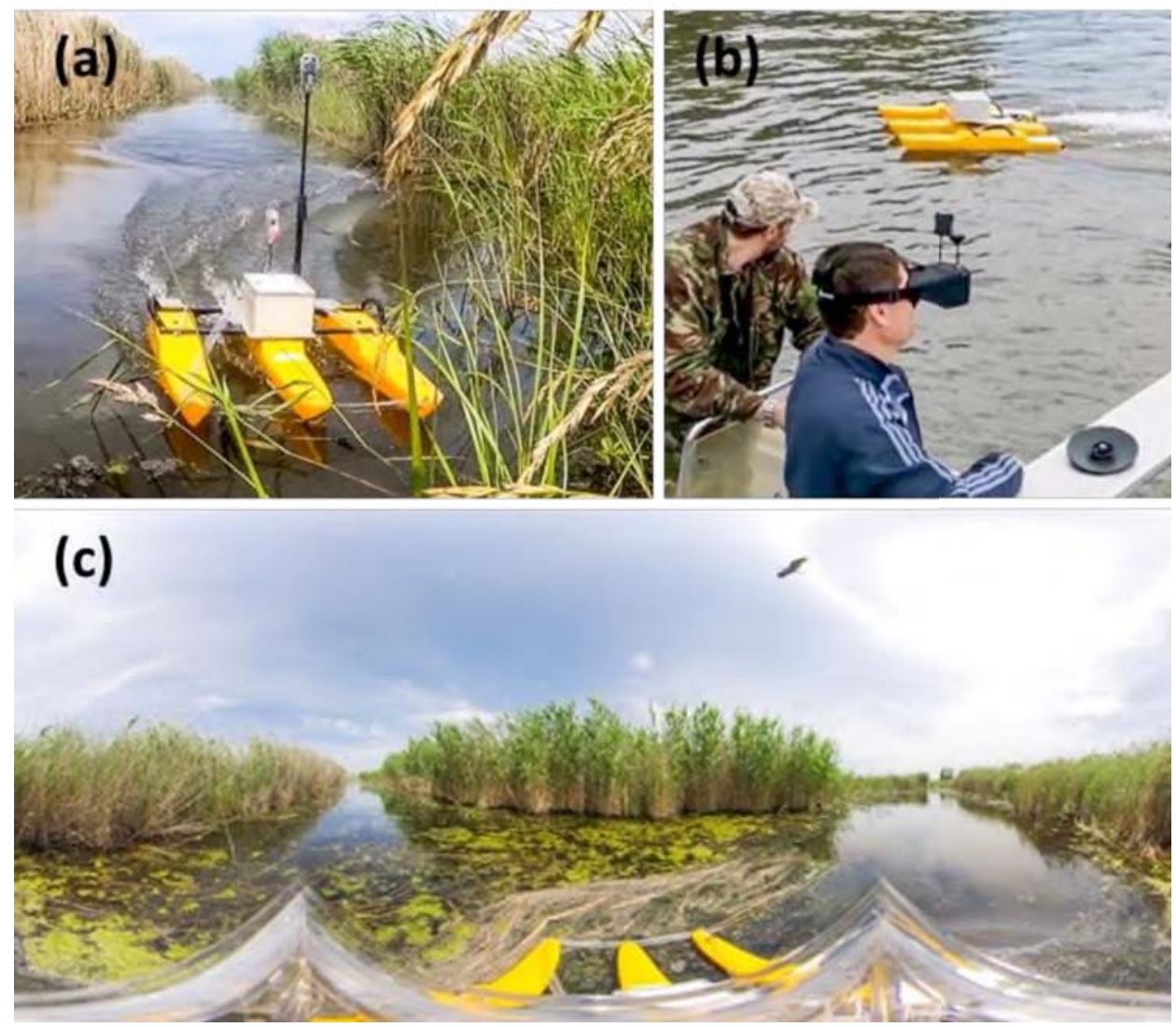

Fig. 3. (a) ARMFC "Vodomerka", (b) the field test of ARMFC, (c) A panoramic view frame from the video stream of VR $360^{\circ}$ camera installed on ARMFC.

Among the advantages is the modular design, which provides the freedom in selecting the equipment according to the needs of a mission. It implies that ARMFC is a multipurpose platform, allowing for different types of field studies. ARMFC has lightweight and powerful engines easing its navigation in shallow waters with abundant vegetation. The remote control in combination with the FPV helmet enables the operator to control functioning and to perform measurements when the vessel is far away and out-of-sight.

The disadvantages were the following: (i) insufficient protection by water intake grids when navigating in waters with rich aquatic vegetation, (ii) a limited radius $(500 \mathrm{~m})$ of transmission between ARMFC and the FPV helmet forced to set the additional starting points for extended reservoirs, (iii) a loud noise of propellers caused birds to become frightened and fly away, constraining to exploit preferentially the standby mode. It is planned to equip ARMFC with an improved antenna with a longer transmission radius up to $2 \mathrm{~km}$ in open areas, and with an automated anchoring system. 
During the explorative missions of ARMFC for the birds counting, the remote panoramic video was filmed in a shallow-water channel and the silted lake (see Fig. 2). At each location, two observation points were chosen, and $80 \mathrm{~min}$ of the panoramic video was recorded totally ( $20 \mathrm{~min}$ per point). Only the panoramic camera provided the account able results because the flying birds were often passing off-sight for the conventional cameras. The end of the missions the recorded video sequences were transferred to a dedicated computer for image processing and analysis.

The results of the visual interpretation of the panoramic video allowed us to find 16 birds. After the mission to the shallow-water channel (Fig. 2), 10 birds were captured and 4 out of 10 were identified. There were two species of the great egret (Egretta alba) and two species of the glossy ibis (Plegadis falcinellus). The mission to the silted lake resulted in 6 birds, and a half of them were identified. There were two species of the glossy ibis (Plegadis falcinellus) and one of the whiskered tern (Chlidonias hybrida). Some of them are presented in Fig. 4. The unidentified birds were either flying too far away or very small and fast flying. All identified species are expected to occur in the explored areas. The population of the glossy ibis is under protection in the Russian Federation; it is listed in the so-called Red Book (a national analog of the IUCN Red List).

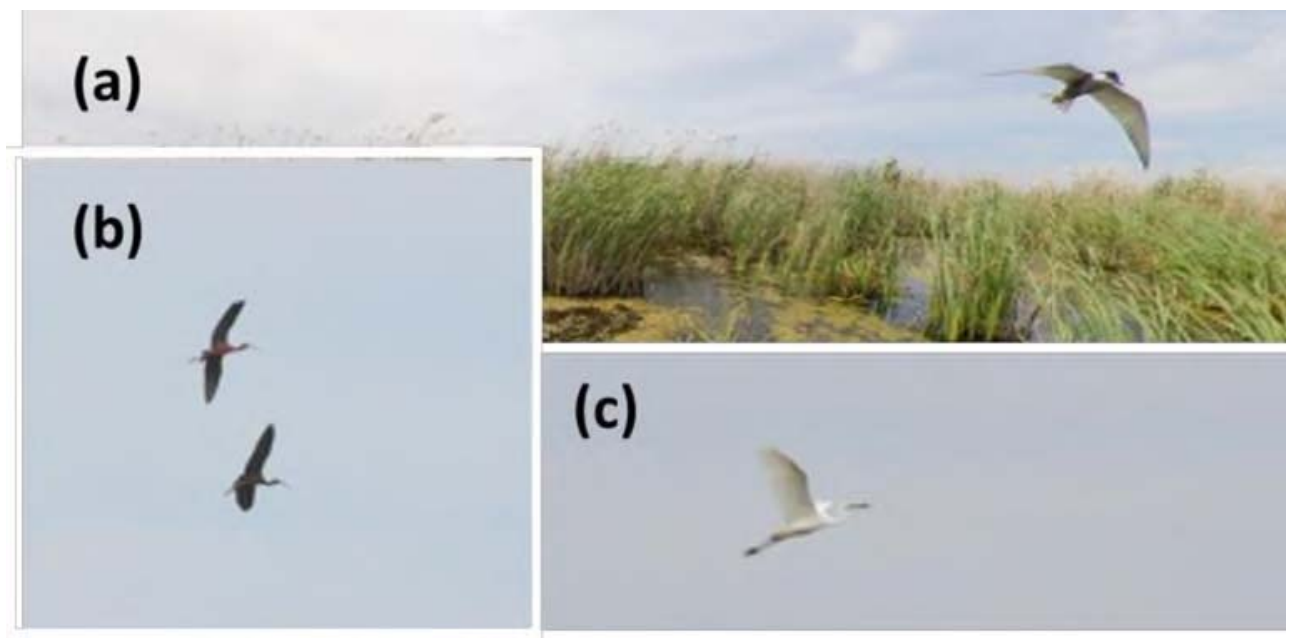

Fig. 4. Fragments of panoramic video images with captured birds during the ARMFC test missions: (a) Chlidonias hybrida, (b) Plegadis falcinellus, and (c) Egretta alba.

The test missions of ARMFC have revealed some disadvantages of the panoramic video recording as a method for the birds counting. They include (i) recording time is limited by the camera's battery charge, which can be extended by supplying it directly from the ARMFC control unit via a USB cable, (ii) fogging of the camera's waterproof box when working in hot weather, which may affect the quality of records, (iii) so far the lengthy process of visual decoding of the captured panoramic video material, which will be automatized in the future by using a dedicated image processing software. Furthermore, moving towards real-time panoramic surveillance of flying birds, it is planned to connect the panoramic video camera to the ARMFC control unit to transmit a video signal over a distance of $400 \mathrm{~m}$.

Besides the technical advances and scientific observations, it was found that the results of panoramic video recording of the avifauna can be effectively used for educational purposes. Professionally edited panoramic video sequences enriched with elements of embedded 3D graphics and text explanations can become a useful virtual reality (VR) simulator for educational courses for ornithologists. For example, one can create a VR 
simulator for remote determination of the species living around a certain water basin. There is also another extension, which might be of interest to the general public and wildlife lovers, in particular. The panoramic bird watching video tours can be developed along with the most remote and inaccessible corners of the deltas of large flat rivers.

Based on the results of the field test phase of ARMFC "Vodomerka" and its employment for identification of the semiaquatic avifauna in shallow areas of the Don River delta, an introductory video was prepared and can be freely accessed (https://vk.com/video-162664826_456239063).

\section{Conclusions}

1. The ARMFC "Vodomerka" was assembled on the hulls of a commercial Riverboat ST platform. It was equipped with modern cameras allowing for remote-controlled navigation and 360-degree surveillance. Thanks to the modular approach to design, the platform may accommodate other scientific equipment to perform contact measurements. The ARMDC is controlled by the operator wearing the FPV helmet, allowing it to navigate out-of-sight. It is characterized by a low manufacturing cost and efficient operation.

2. Several shallow areas of the Don River delta were explored for the first time thanks to the ARMFC capabilities to navigate in hardly accessible areas. The test missions provided 80 min of panoramic video, where 7 out of 16 birds were identified, including the Plegadis falcinellus, whose population is under protection in the Russian Federation.

3. The panoramic video records can serve for educational purposes and wildlife promotion.

The study is carried out within the framework of the state task of Federal Research Centre The Southern Scientific Centre of the Russian Academy of Sciences (SSC RAS), state registration of the project is No.AAAA-A19-119040390084-3.

\section{References}

1. G. Matishov, D. Matishov, O. Arkhipova, et al., Ecological Atlas of the Sea of Azov ISBN 978-5-4358-0020-3 (2011)

2. R. Savitskiy, Avifauna of the Sea of Azov and the Eastern Priazovie in the modern period, Birds of the northern and southern seas of Russia: fauna, ecology, 215-231 ISBN 978-5-91137-225-5 (2013)

3. G. Matishov, R. Savitskiy, Waterfowls' death rate in the Sea of Azov, Bulletin of the Southern Scientific Center, 8(3), 50-54 (2012) doi:10.13140/RG.2.1.3527.3124

4. V. Fedyaeva, A. Shmaraeva et al., Nature reserve fund of the Quiet Don (2018) ISBN 978-5-6040602-8-5

5. A. Zabashta, M. Zabashta, Breeding colonies of birds in the lower reaches of the Don (Don-Aksai loan - Don delta), Kagalnik, Mius and the eastern part of Taganrog Bay, The Russian Journal of Ornithology, 29(1924), 2205-2233 (2020)

6. E. Karabanina, S. Simonov, Comparison analysis of the bird line transect census methods: the finish line transect method and the modified Kumari's methodology, The herald of game management, 15(4), 246-250 (2018)

7. N. Chelintsev, Mathematical bases of moving animal surveys, Bulletin of Moscow society of naturalists. Biological series, 118(1), 3-15 (2013)

8. S. Simonov, D. Panchenko, K. Tirronen, V. Belkin, Experience of aerial surveys for countings of tetraonids in Karelia, The herald of game management, 15(4), 242-245 (2018) 
9. C.-Y. Choi, X. Xiao, J. Takekawa, et al., Low survival rates of Swan geese (Ansercygnoides) estimated from neck-collar resighting and telemetry, Waterbirds, 39(2), 136-145 (2016) doi:10.1675/063.039.0307

10. O. Onmus, M. Siki, Shorebirds in the Gediz Delta (Izmir, Turkey): breeding and wintering abundances, distributions, and seasonal occurrences, Turkish Journal of Zoology, 35(5), 615-629 (2011) doi:10.3906/zoo-1002-14

11. N. Schumann, J. Arnould, P. Dann, Use of terrestrial habitats by burrow-nesting seabird sin south-eastern Australia, Emu, 113(2), 135-144 (2013) doi:10.1071/MU12088.

12. R. Savitskiy, G. Matishov, Winter ecology of the Smew (Mergusalbellus) in the Sea of Azov, Russian Journal of Ecology, 42(3), 260-262 (2011) doi:10.1134/S1067413611030143

13. G. Rishworth, D. Green, P. Pistorius, Y. Tremblay, An automated approach towards measuring time-activity budgets in colonial seabirds, Methods in Ecology and Evolution, 5(9), 854-863 (2014) doi:10.1111/2041-210X.12213

14. D. Karuthedathu, J. Praveen, M. Palot, Recent trends in marine bird monitoring in India, Journal of the Bombay Natural History Society, 109(1,2), 53-59 (2012)

15. D. Lyakhov, A. Kim, D. Minaev, Development and field trials of small telecommand ship, Underwater Investigations and Robotics, 1, 48-57 (2014)

16. E. Ackerman, Unmanned cargo ships face industry resistance, are a good idea anyway, IEEE Spectrum, 87 (2014)

17. G. Ferri, A. Manzi, F. Fornai, et al., The HydroNet ASV, a small-sized autonomous catamaran for real-time monitoring of water quality: From design to missions at sea, IEEE J Ocean Eng, 40(3), 710-726 (2015) doi.org/10.1109/JOE.2014.2359361

18. A. Barry, J.-L. Liardon, P. Paccaud, et al., A low-cost, autonomous mobile platform for limnological investigations, supported by high-resolution mesoscale airborne imagery, PLoS ONE, 14(2), Article e0210562 (2019) doi.org/10.1371/journal.pone.0210562 